\title{
PROTEÇÃO DA MARCA NO AMBIENTE VIRTUAL: O SISTEMA DE LINKS PATROCINADOS
}

\author{
Guilherme Sorg Cabral ${ }^{1}$ \\ https://orcid.org/0000-0002-2504-0290 \\ http://lattes.cnpq.br/8855508508048558
}

\author{
RECEBIBO 29/01/2019 \\ APROVADO 30/01/2019 \\ PUBLICADO 04/01/2019 \\ Editor Responsável: Carla Caldas \\ Método de Avaliação: Double Blind Review \\ E-ISSN: 2316-8080 \\ DOI: 10.16928
}

RESUMO

Este artigo traz um estudo sobre a utilização de marca registrada nas campanhas de marketing virtual conhecidas como links patrocinados. Serão abordados em quais casos terceiros podem valer-se de marcas registradas para dar destaques em sua publicidade on-line e as situações que tal prática é considerada abusiva e enseja responsabilização e consequente dever de reparação de danos, tanto por parte daquele que publica o anúncio quanto do provedor de aplicação que disponibiliza o serviço de links patrocinados.

Palavras-chave: Marca. Link patrocinado. AdWords.

\section{RESUMEN}

Este artículo trae un estudio sobre el uso de marca registrada en las campañas de marketing virtual conocidas como enlaces patrocinados. Se abordarán en cuáles casos terceros pueden valerse de marcas registradas para dar destaque en su publicidad en línea y las situaciones que tal práctica es considerada abusiva y da la responsabilidad y consecuente obligación de reparación de daños tanto por parte de aquel que publica el anuncio como del proveedor de aplicación que ofrece el servicio de enlaces patrocinados.

PALABRAS CLAVE: MARCA. ENLACE PATROCINADO., ADWORDS.

\footnotetext{
1 Bacharel em Ciência da Computação pela Faculdade Planalto, Graduando do $9^{\circ}$ semestre do Curso de Direito da Universidade Paulista, cabraus@gmail.com, Faculdade de Direito da Universidade Paulista - Campus Bauru/SP, número de identificação ORCID: https://orcid.org/0000-0002-2504-0290
} 


\section{INTRODUÇÃO}

Marca pode ser definida como sendo um sinal visualmente perceptível capaz de distinguir os produtos ou serviços de uma empresa, principalmente, em relação a outros concorrentes (JUNGMANN, 2010). Mais do que isto, a marca constitui patrimônio valioso para seu titular, que a constrói geralmente empregando volumosas quantidades de recursos. Este é um dos motivos que atribuem relevância à sua proteção.

O volume de negócios realizados em ambiente virtual cresce solidamente a cada ano e a atuação das empresas na internet assume seu protagonismo, principalmente para grandes corporações.

Desta forma, a exposição das marcas em ambiente virtual é cada vez mais constante e, ao contrário do que ocorria com a publicidade nas mídias que precedem à internet, as quais sofriam limitações físicas (o espaço disponível nas páginas de um jornal ou revista, ou o tempo livre na televisão para a exibição de comerciais) que tornavam a publicidade bastante onerosa e por consequência menos acessível, atualmente manter um site ou contratar serviços de anúncios em redes sociais ou em buscadores de conteúdo, é algo exequível a praticamente qualquer pessoa.

A facilidade e o baixo custo de se anunciar na internet, porém, traz consigo um maior potencial para a ocorrência de violações à proteção dos signos distintivos.

No Brasil, a propriedade das marcas tem estatura de direito fundamental constitucionalmente previsto no inciso XXIX do artigo $5^{\circ}$ da lei maior ${ }^{2}$. Ocorrendo violação ao direito de propriedade da marca o titular pode exigir do Estado a prestação da tutela jurisdicional, tendo, em alguns casos, consequências penais para o infrator.

No decorrer deste trabalho será demonstrada a importância dos signos distintivos para as organizações, o modo de funcionamento do serviço de links patrocinados, e como o Tribunal de Justiça do Estado de São Paulo tem aplicado o direito nacional nas lides envolvendo o desrespeito ao direito marcário neste tipo específico de marketing virtual. Como insumo para a análise das decisões, nos conflitos envolvendo o tema, foi utilizada a base de jurisprudência da corte paulista disponibilizada na rede mundial de computadores ${ }^{3}$.

\footnotetext{
${ }^{2}$ A Constituição Federal de 1988 traz a seguinte redação em seu artigo 5, XXIX: "a lei assegurará aos autores de inventos industriais privilégio temporário para sua utilização, bem como proteção às criações industriais, à propriedade das marcas, aos nomes de empresas e a outros signos distintivos, tendo em vista o interesse social e o desenvolvimento tecnológico e econômico do País;".

${ }^{3}$ Consulta Jurisprudencial realizada no endereço eletrônico <https://esaj.tjsp.jus.br/cjsg/consultaCompleta.do>.
} 
Na consulta jurisprudencial não se utilizou parâmetros de limitação temporal inicial, ou seja, para a pesquisa foram consideradas todas as decisões sobre o tema proferidas pelo tribunal até 16 de fevereiro de 2017.

Foram avaliadas também as políticas de utilização do serviço de links patrocinados Google AdWords, responsável pela quase totalidade das pesquisas realizadas na rede no país.

Com isto, procurou-se apurar o tratamento dado pelo Tribunal de Justiça de São Paulo nos casos de utilização por terceiros de marca protegida em sistemas de links patrocinados, apurando as situações em que os limites do direito de propriedade da marca permitem sua utilização por terceiros e nos casos de transgressão quais as consequências, na esfera civil, para o infrator.

\section{A IMPORTÂNCIA DAS MARCAS NO AMBIENTE VIRTUAL}

A marca, para o direito brasileiro, é todo sinal visualmente perceptível, ressalvadas as exceções legais ${ }^{4}$, e que exerce uma das seguintes funções: (1) distinguir produtos e serviços semelhantes ou afins - pode-se dizer que esta é sua principal função - (2) atestar a conformidade de um produto ou serviço com determinadas normas ou especificações - marca de certificação - e, (3) identificar que um produto ou serviço provém de um membro de uma determinada entidade - marca coletiva. Para este estudo são relevantes as marcas que tem como função a diferenciação de produtos e serviços semelhantes.

Em outubro de 2016 a Revista Forbes publicou ranking enumerando as 50 marcas mais valiosas do planeta. Vale ressaltar que, das dez primeiras posições, cinco são do setor tecnológico e duas destas têm suas operações essencialmente ligadas ao ambiente on-line. São elas o Google, que tem quase a hegemonia mundial em termos de mecanismo de busca na internet, e a Amazon, que sempre figura entre as maiores lojas de e-commerce do mundo. Sendo que a marca Google ocupa a segunda posição da lista atrás somente da fabricante de eletrônicos Apple. A marca do buscador de conteúdo foi avaliada em US\$ 133,252 bilhões (FORBES, 2016), para fins comparativos pode-se eleger como parâmetro a informação publicada pela revista VEJA, em agosto de 2016, em matéria sobre o crescimento de 53\% do valor de mercado das empresas brasileiras em 2016. O valor total das empresas brasileiras listadas em Bolsa de Valores após essa grande valorização totalizava US\$ 715,7 bilhões (LIMA, 2016). Ou seja, apenas o valor da marca (não o valor total da empresa) Google

\footnotetext{
${ }^{4} \mathrm{O}$ artigo 124 da Lei 9.279/96 - Lei de Propriedade Industrial - traz um rol dos símbolos que não podem ser registrados como marca. PIDCC, Aracaju/Se, Ano VIII, Volume 13 no 01, p.277 a 300 Fev/2019 | www.pidcc.com.br
} 
correspondia, à época, ao equivalente a 18,6\% do valor de todas as empresas brasileiras listadas em bolsa de valores em agosto de 2016, após uma valorização de 53\%.

A marca, em muitos casos, pode ser o bem mais valioso de uma empresa e a sua exposição na internet atualmente é praticamente inevitável não somente para as empresas voltadas à tecnologia e ao ambiente on-line, mas como prestadores de serviços e aqueles comercializam produtos. $\mathrm{O}$ comércio virtual nacional vem crescendo continuamente mesmo nos períodos de crise quando a economia em geral se retrai.

No ano de 2015, 39,1 milhões de consumidores virtuais realizaram pelo menos uma compra, um volume 3\% maior do que 2014, movimentando um total de R\$ 41,3 bilhões no ano (WEBSHOPPERS, 2016, p. 16), vale lembrar que o Produto Interno Bruto do País em 2015 teve uma retração de 3,8\% (IBGE, Contas Nacionais Trimestrais, 2016) e, ainda assim o e-commerce cresceu $3 \%$ em número de consumidores e $15 \%$ em valor nominal em relação ao ano anterior.

No Brasil, só no primeiro semestre de 2016, 23,1 milhões de consumidores realizaram pelo menos uma compra virtual e movimentaram R \$ 19,6 bilhões (WEBSHOPPERS, 2016, p. 15), o número é basicamente cem vezes maior do que o faturamento do primeiro semestre de 2001 que foi de 197 milhões. Em julho de 2005, cerca de quatro milhões de pessoas haviam feito pelo menos uma compra em loja virtual brasileira desde o ano 2000 (WEBSHOPPERS, 2005, p. 9/11), ao passo que, só nos seis meses iniciais de 2016, 23,1 milhões de pessoas realizaram pelo menos uma compra.

Se por um lado as marcas são bens valiosos que devem ser protegidos, por outro, a sua exposição e utilização no ambiente virtual é inevitável para as empresas que visam expandir seus negócios. O marketing virtual torna-se cada vez significativo e atualmente uma das formas mais utilizadas nesta modalidade publicitária são os links patrocinados.

\section{O QUE SÃO LINKS PATROCINADOS?}

Trata-se de uma das modalidades possíveis em termos de marketing virtual que vem ganhando cada vez mais relevância e sendo utilizada por um número cada vez maior de empresas.

O consumidor que deseja acessar um site de internet, para realizar uma compra ou mesmo para obter informações sobre produtos e serviços, ele pode fazê-lo, em regra, de duas maneiras: (1) digitando o endereço eletrônico (URL - Uniform Resource Locator) do site em seu navegador (www.apple.com, por exemplo) ou (2) procurando pela empresa em um buscador como Google, Bing, Yahoo!, entre outros. É nessa segunda forma de acesso descrita que o internauta terá contato com os anúncios contratados através dos sistemas de links patrocinados.

PIDCC, Aracaju/Se, Ano VIII, Volume 13 no 01, p.277 a 300 Fev/2019 | www.pidcc.com.br 
"Os links patrocinados são anúncios pagos, inseridos ao lado das buscas, que são exibidos quando o consumidor busca com determinadas palavras-chave" (TORRES, 2010, p. 47). Por exemplo, um fictício vendedor de maçãs que atua no município de Bauru/SP, pode contratar o serviço de um buscador para que seu anúncio seja exibido, em destaque, como resultado de pesquisa realizada contendo os termos "maçã" e "Bauru".

Este formato revolucionou a maneira de se anunciar produtos e serviços. Rapidamente e a baixíssimo custo é possível contratar o serviço, parametrizar a exibição do anúncio que pode ser disponibilizado em todo o planeta, ou restrito a um país ou região, pode-se também indicar se a publicidade estará disponível 24 horas todos os dias ou apenas no período noturno dos finais de semana, por exemplo, tudo isso ligado a palavras-chave definidas na contratação do serviço que irão atrelar a aparição da publicidade com a pesquisa realizada pelo usuário no sistema de busca na internet e, ao contrário de anúncios veiculados em jornais, revistas, rádio, televisão ou qualquer outro meio tradicional, o pagamento pelo serviço tem como base de cálculo a quantidade de cliques no anúncio, ou seja, o anunciante não paga pela simples exibição, mas pela quantidade de visitas que seu site efetivamente teve em decorrência do link patrocinado (JACOBSON, 2009).

Atualmente praticamente todos os sistemas de busca na internet tem seu serviço de links patrocinados, neste estudo restringiu-se o escopo ao serviço prestado pelo Google, o chamado Google AdWords.

\subsection{Google AdWords}

Seria demasiadamente extenso o trabalho se este abrangesse todos os serviços de links patrocinados presentes no Brasil, desta forma, para que se pudesse analisar as políticas e os termos do serviço elegeu-se o Google AdWords. Tal escolha se deu com base na sua relevância medida pelo volume de pesquisas realizadas no buscador do Google em comparação com seus concorrentes. Em consulta à base de dados do StatCounter - Global Stats ${ }^{5}$ que mantém informações sobre o percentual de utilização dos sistemas de busca disponíveis na internet verificou-se que, no Brasil, em fevereiro de 2017, o Google detinha 97,21\% das buscas realizadas no país. Isto posto, ao dissecar o serviço de marketing virtual do Google abarca-se quase a totalidade de exibições de anúncios contratados por meio de link patrocinado no país.

\footnotetext{
${ }^{5}$ Disponível em: $<$ http://gs.statcounter.com/search-engine-market-share/all/brazil >. Acesso em 03 Mar 2017. 
A característica mais relevante do Google $A d W o r d s$ para este estudo é a vinculação da publicidade às palavras-chave utilizadas nas pesquisas, pois é neste vínculo que potencialmente ocorrem as violações da propriedade de marca neste tipo de serviço. Pode ser citado como exemplo o Processo 1015330-08.2015.8.26.0224 do Tribunal de Justiça de São Paulo, que teve como autora CVC BRASIL OPERADORA E AGÊNCIA DE VIAGENS S.A. e no polo passivo da ação figurava DECOLAR.COM LTDA. A ré contratou o serviço de publicidade do Google vinculando os termos "CVC cruzeiros" e "CVC hotéis" aos seus anúncios publicitários. Assim, quando o potencial cliente realizava pesquisa com as referidas expressões, recebia como resposta, em destaque, anúncios da empresa Decolar.com, apesar de ter se valido em sua pesquisa da marca registrada "CVC" de titularidade de empresa concorrente. O Poder Judiciário entendeu a prática como lesiva ao direito marcário. A decisão em primeira instância foi favorável à autora e posteriormente confirmada pelo tribunal em nível recursal. O julgamento da apelação ocorreu em 18 de maio de 2016 com a seguinte ementa:

MARCA. OBRIGAÇÃO DE NÃO FAZER C.C. REPARAÇÃO DE DANO. LINK PATROCINADO. Uso da marca da autora como palavra chave de link patrocinado contratado pela ré. O consumidor que fazia uma busca na internet pelo nome da autora obtinha como resposta, dentre as opções, o site da requerida. Uso parasitário da marca. Dano moral presumido. Lesão à honra, reputação e imagem da autora que, ao lado do uso parasitário do nome da sociedade empresária, deve ser indenizado. A quantia de $\mathrm{R} \$ 50.000,00$ está adequada aos parâmetros do art. 944, do CC, o que justifica sua preservação. Não provimento.

(TJ-SP; Relator (a): Enio Zuliani; Comarca: Guarulhos; Órgão julgador: $1^{\text {a }}$ Câmara Reservada de Direito Empresarial; Data do julgamento: 18/05/2016).

Realizada análise dos termos e políticas do serviço Google AdWords, descobriu-se que existem restrições para a utilização de marca registrada no corpo dos anúncios veiculados, o mesmo não ocorre no emprego de termo que corresponda a signo protegido como palavra-chave. $\mathrm{O}$ texto dos Termos do Programa de Publicidade do Google ${ }^{6}$ não regula de forma direta o tema, mas faz referência às Políticas do Google $A d W o r d s^{7}$ que tratam da utilização de marcas registras no sistema de publicidade em estudo. A seção "Conteúdo Restrito" das Políticas do Google AdWords traz, entre outros, o tópico "Marcas Registradas" ${ }^{8}$ que dispõe o tratamento dispensado às expressões registradas como marca e sua utilização em seu programa de marketing virtual. Seguem os trechos mais relevantes da política quanto ao uso de marcas registradas (grifo no original):

\footnotetext{
6 Disponível em: <https://bpui0.google.com/billing/ui/static/terms and conditions/TC-BRL-201308-Brazil-Portuguese.html>. Acesso em: 02 Mar 2017.

${ }^{7}$ Disponível em: $<$ https://support.google.com/adwordspolicy/answer/6008942?hl=pt-BR $>$. Acesso em 02 Mar 2017.

${ }^{8}$ Disponível em: $<$ https://support.google.com/adwordspolicy/answer/6118> . Acesso em 03 Mar 2017.
} 


\section{Abordagem do Google em relação a marcas registradas}

Se o proprietário de uma marca registrada envia uma reclamação ao Google sobre o uso da marca registrada dele em anúncios de texto do Google AdWords, o Google analisa a reclamação e pode impor determinadas restrições sobre o uso dessa marca registrada.

Existem vários fatores que determinam quando as marcas registradas podem ser usadas em anúncios de texto do Google AdWords. Junto com os fatores descritos abaixo, essas políticas se aplicam somente quando um proprietário da marca registrada envia uma reclamação válida para o Google.

\section{Marcas registradas em textos de anúncios}

O Google analisa as reclamações e pode restringir o uso de uma marca registrada nos textos de anúncios. A exibição dos anúncios do Google AdWords não é permitida quando o texto dos anúncios contém marcas registradas restritas. Essa política aplica-se em todos os países.

\section{Marcas registradas como palavras-chave}

O Google não investiga ou restringe a seleção de marcas registradas como palavras-chave, mesmo que recebamos uma reclamação de marca registrada.

Constata-se que Google não realiza uma filtragem prévia no conteúdo do anúncio veiculado ou nas palavras-chave empregadas para verificar se existem marcas registradas sendo utilizadas em anúncios. A empresa age, de forma reativa, diante da reclamação do titular de uma marca que figure, sem autorização, em texto de anúncio veiculado através do seu serviço de link patrocinado. $\mathrm{O}$ que merece destaque é o tratamento dado às palavras-chave que, mesmo diante de uma reclamação do titular da marca decorrente da utilização indevida do sinal distintivo protegido, não há restrição em sua utilização e sequer investigação do fato.

Existem dois tratamentos distintos a depender de como uma marca protegida é empregado nos Google AdWords. Quanto ao conteúdo de um anúncio, terceiros não podem se valer de signo registrado como marca, cabendo a fiscalização ao titular do registro. Já no tocante às palavras-chave é permitida sua utilização não havendo restrição nem mesmo após manifestação do titular da marca. Assim, pode-se extrair das políticas do serviço que o Google entende a utilização de marca registrada em texto de anúncio de terceiro como violação da proteção garantida pela propriedade industrial, porém, o mesmo não ocorre na vinculação de signo distintivo protegido a anúncio de empresas não autorizadas através de palavra-chave.

A seguir analisa-se a proteção da marca concedida pelo ordenamento jurídico nacional para, posteriormente, examinar os termos e políticas do serviço do Google à luz das normas relativas à propriedade industrial e da Jurisprudência do Tribunal de Justiça do Estado de São Paulo. 


\section{PROTEÇÃO DA MARCA}

O ordenamento pátrio, desde a Constituição de 1891, elevou ao nível constitucional a proteção das marcas (REQUIÃO, 2003), o texto constitucional trazia em seu artigo 72, § 27 que “A lei assegurará a propriedade das marcas de fabrica"; a Carta de 1934 manteve a previsão em seu artigo 113; a lei maior de 1937 limitou-se a atribuir competência legislativa privativa à União referente à proteção das marcas (art. 16, XXI); em 1946 a propriedade das marcas voltou a figurar como direito constitucionalmente garantido (art. 141, § 18); o texto de 1967 manteve a estatura constitucional do direito de marca (art. 150, $\S 24$ ); atualmente nossa lei maior traz o direito de propriedade da marca como direito fundamental insculpido no inciso XXIX de seu artigo $5^{\circ}$, com a seguinte redação:

XXIX - a lei assegurará aos autores de inventos industriais privilégio temporário para sua utilização, bem como proteção às criações industriais, à propriedade das marcas, aos nomes de empresas e a outros signos distintivos, tendo em vista o interesse social e o desenvolvimento tecnológico e econômico do País;

Nota-se que, bem como o direito à propriedade (gênero) que foi relativizado pela carta constitucional ao atrelá-lo à sua função social ${ }^{9}$, a propriedade das marcas (espécie) depende da observância do interesse social, bem como do desenvolvimento tecnológico e econômico do país.

A Constituição Federal institui o direito às marcas, porém, sua regulamentação fica a cargo de normas infraconstitucionais, sendo a principal delas a Lei 9.279/96 - Lei de Propriedade Industrial. À luz da Constituição da República a propriedade das marcas não pode afrontar o interesse social assim como também não pode constituir barreira ao desenvolvimento tecnológico e econômico do país, neste sentido a lei traz algumas limitações ao direito de propriedade da marca, em especial as previstas em seu artigo 132 e incisos.

A propriedade da marca é adquirida através do registro validamente expedido e ao titular de marca de produto ou serviço é assegurado o uso exclusivo em todo o território nacional, conforme preconiza o caput do artigo 129 da Lei $9.279 / 96^{10}$. No Brasil o órgão responsável pelo registro de marcas é o Instituto Nacional da Propriedade Industrial - INPI - e, o procedimento para a concessão do registro leva de dois a cinco anos (INPI, 2013, p. 13), porém a Lei de Propriedade Industrial já

\footnotetext{
${ }^{9}$ Art. $5^{\circ}$, inciso XXIII da Constituição Federal: "a propriedade atenderá a sua função social"

${ }^{10}$ Art. 129. A propriedade da marca adquire-se pelo registro validamente expedido, conforme as disposições desta Lei, sendo assegurado ao titular seu uso exclusivo em todo o território nacional, observado quanto às marcas coletivas e de certificação o disposto nos arts. 147 e 148 .

$\S 1^{\circ}$ Toda pessoa que, de boa fé, na data da prioridade ou depósito, usava no País, há pelo menos 6 (seis) meses, marca idêntica ou semelhante, para distinguir ou certificar produto ou serviço idêntico, semelhante ou afim, terá direito de precedência ao registro.

$\S 2^{\circ} \mathrm{O}$ direito de precedência somente poderá ser cedido juntamente com o negócio da empresa, ou parte deste, que tenha direta relação com o uso da marca, por alienação ou arrendamento.
} 
garante, em seu artigo 130 e incisos, àquele que deposita pedido de registro da marca junto ao INPI alguns direitos, entre eles o de ceder o pedido de registro, licenciar o uso da marca e zelar pela sua integridade material ou reputação.

Para Denis Borges Barbosa (BARBOSA, 2010, p. 702) os signos visuais devem obedecer aos requisitos de distintividade, veracidade e novidade relativa para que possam ser registrados como marca.

A respeito da distintividade diz Barbosa:

É distintivo, objetivamente considerado, o que não tem características próprias, o que não significa, de forma a desempenhar a função marcária que lhe é própria. Assim, uma marca de fantasia, sem o enfraquecimento causado pela evocatividade, como as clássicas kodak ou xerox. (grifo do autor).

O signo deve trazer identidade ao produto ou serviço, de forma a não gerar confusão para o consumidor. Assim o sinal deve, de pronto, remeter o consumidor ao produto ou serviço específico não podendo referenciar a características genéricas, ou formas necessárias de sua apresentação.

A veracidade "é a exigência de que o signo não seja intrinsicamente deceptivo, de forma a lesar seja o consumidor, seja o competidor" (BARBOSA, 2010, p. 703). Não são admitidos sinais que possam induzir o consumidor ao erro, para fins exemplificativos, um signo que tenha em sua composição a palavra "abelha" não pode ser utilizado em produto com aspecto semelhante ao mel produzido pelas abelhas, mas que em verdade é composto de Glucose de milho e açúcar.

"A novidade relativa constitui apenas o requisito de que a marca tem de se distinguir dos outros signos já apropriados por terceiros" (BARBOSA, 2010, p. 704). Aqui se destaca que não há necessidade de ineditismo. A proteção marcária atende ao Princípio da Especialidade das Marcas que limita a regra da novidade relativa a um mercado específico onde efetivamente haja concorrência (BARBOSA, 2007). Ao depositar junto ao INPI o pedido de registro de uma marca o depositante deve indicar, utilizando o Sistema de Classificação Internacional de Marcas (também conhecido como sistema de Nice), que contém 34 classes de produtos e 11 classes de serviços, para quais classes de produto ou serviço a proteção está sendo requerida (INPI, 2013, p. 15). Dessa forma para uma marca qualquer cujo depositante queria proteção no ramo de fabricação ou comercialização de bicicletas, deverá fazer o registro na classe 12 "Bicicletas", e a proteção obtida e o direito à exclusividade alcançam apenas este ramo de atividade. Nada impede que mais tarde seja concedido registro a outrem para utilizar a mesma marca - idêntica ou semelhante - para comercializar, por exemplo, azulejos (classe 19). 
Pode-se questionar então se seria possível, por exemplo, o registro da marca "Coca-Cola Corretagens Imobiliárias" para um serviço de corretagem (classe 36). A resposta é não! E isso não depende da existência de registro da marca Coca-Cola na classe 36. Trata-se de exceção ao Princípio da Especialidade - A marca de alto renome - trazida pelo artigo 125 da Lei de Propriedade Industrial diz que "À marca registrada no Brasil considerada de alto renome será assegurada proteção especial, em todos os ramos de atividade" (grifo nosso). Do dispositivo legal tiramos dois requisitos básicos para que uma marca obtenha a proteção em todos os ramos de atividade: (1) ser a marca registrada no Brasil e; (2) ser reconhecida como de alto renome.

A Lei de Propriedade Industrial traz o instituto da marca de alto renome, porém é omissa quanto aos requisitos para que se reconheça um signo distintivo como tal. A competência para o reconhecimento do alto renome, bem como para regulamentar o procedimento para tanto, é do INPI, tal atribuição foi reconhecida pelo STJ no julgamento do Recurso Especial No 1.162.281 - RJ, de relatoria da Ministra Nancy Andrighi.

COMERCIAL E PROCESSUAL CIVIL. MARCA. ALTO RENOME. DECLARAÇÃO. PROCEDIMENTO. CONTROLE PELO PODER JUDICIÁRIO. LIMITES.

1. Embora preveja os efeitos decorrentes do respectivo registro, o art. 125 da LPI não estabeleceu os requisitos necessários à caracterização do alto renome de uma marca, sujeitando o dispositivo legal à regulamentação do INPI.

2. A sistemática imposta pelo INPI por intermédio da Resolução $\mathrm{n}^{\circ} 121 / 05$ somente admite que o interessado obtenha o reconhecimento do alto renome de uma marca pela via incidental.

3. O titular de uma marca detém legítimo interesse em obter, por via direta, uma declaração geral e abstrata de que sua marca é de alto renome. Cuida-se de um direito do titular, inerente ao direito constitucional de proteção integral da marca.

4. A lacuna existente na Resolução ${ }^{\circ} 121 / 05$ - que prevê a declaração do alto renome apenas pela via incidental - configura omissão do INPI na regulamentação do art. 125 da LPI, situação que justifica a intervenção do Poder Judiciário.

5. Ainda que haja inércia da Administração Pública, o Poder Judiciário não pode suprir essa omissão e decidir o mérito do processo administrativo, mas apenas determinar que o procedimento seja concluído em tempo razoável. Dessa forma, até que haja a manifestação do INPI pela via direta, a única ilegalidade praticada será a inércia da Administração Pública, sendo incabível, nesse momento, a ingerência do Poder Judiciário no mérito do ato omissivo.

6. Por outro lado, os atos do INPI relacionados com o registro do alto renome de uma marca, por derivarem do exercício de uma discricionariedade técnica e vinculada, encontram-se sujeitos a controle pelo Poder Judiciário, sem que isso implique violação do princípio da separação dos poderes.

7. Recurso especial a que se nega provimento.

(Relator (a): Ministra Nancy Andrighi; Data do julgamento: 19/02/2013). 
Destaca-se aqui que a época da decisão supracitada (fevereiro de 2013) o procedimento para reconhecimento do alto renome de uma marca só era possível de ser solicitado reativamente, na tentativa de terceiro em registrar a marca em outra classe de produto ou serviço. Porém, em 19 de agosto de 2013 foi editada pelo INPI a Resolução 107/2013 (alterada em 18 de outubro de 2016 pela Resolução 172/2016) que trouxe em seu art. $1^{\circ}, \S 2^{\circ}$ a possibilidade de reconhecimento do alto renome como um procedimento autônomo, ou seja, atualmente é possível dar início ao procedimento sem que haja prévia tentativa de registro da marca candidata à proteção especial em outra classe do sistema de Nice. Já os requisitos necessários para a comprovação do alto renome são descritos no art. $3^{\circ}$ da Resolução 107/2013 (neste ponto alterado pela Resolução 172/2016).

\section{DA COMPROVAÇÃO DO ALTO RENOME}

Art. $3^{\circ}$ A comprovação da alegada condição de alto renome deverá estar vinculada a três quesitos fundamentais:

I. Reconhecimento da marca por ampla parcela do público brasileiro em geral; (Redação dada pela Resolução no 172/2016)

II. Qualidade, reputação e prestígio que o público associa à marca e aos produtos ou serviços por ela assinalados; e

II. Qualidade, reputação e prestígio que o público brasileiro em geral associa à marca e aos produtos ou serviços por ela assinalados; e (Redação dada pela Resolução no 172/2016)

III. Grau de distintividade e exclusividade do sinal marcário em questão.

Uma vez reconhecido o alto renome o INPI anota esta condição no registro da respectiva marca, e tal anotação, em regra, perdura por $10(\mathrm{dez})$ anos, conforme preconiza o art. $8^{\circ}$ e seu parágrafo único da Resolução 107/2013.

No momento da realização deste estudo, a última publicação do INPI listando as marcas de alto renome vigentes ocorreu em 13/12/2016 e trouxe 20 (vinte) marcas consideradas de alto renome e mais três em trâmite judicial ${ }^{11}$. Para ilustrar o quão rigoroso é tal procedimento, apenas no período de janeiro a dezembro de 2016 foram depositados 166.368 (cento e sessenta e seis mil trezentos e sessenta e oito) pedidos de registro de marca $^{12}$, enfatiza-se que este não é o total de marcas registradas, mas sim o número de pedidos de registro apenas no ano de 2016. É fato que a grande maioria delas, muito provavelmente, nunca irá requerer o alto renome, a informação foi trazida aqui

11 Disponível em: <http://www.inpi.gov.br/menu-servicos/marcas/arquivos/inpi-marcas -marcas-de-alto-renome-em-vigencia -1312-2016 padrao.pdf/view>. Acesso em 03 Mar 2017.

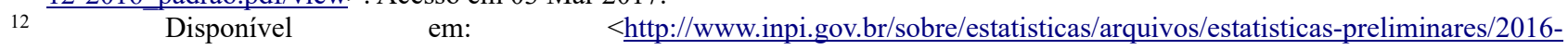
12 12_desagregadas_depositos.xls $>$. Acesso em 03 Mar 2017

PIDCC, Aracaju/Se, Ano VIII, Volume 13 no 01, p.277 a 300 Fev/2019 | www.pidcc.com.br 
apenas para ilustrar o percentual ínfimo dentre as marcas registradas que são consideradas como sendo de alto renome.

Outra forma de proteção que devemos citar é a concedida à marca notoriamente conhecida, esta decorre da Convenção da União de Paris (CUP), tratado de propriedade industrial firmado inicialmente em 1883, do qual o Brasil é signatário desde sua criação. Ela difere da proteção concedida à marca de alto renome em diversos aspectos, sendo dois deles os mais relevantes para o tema em pauta: (1) A proteção abrange apenas o ramo de atividade em que se utiliza a marca notoriamente conhecida; (2) Não há necessidade do registro da marca no Brasil para que ela seja protegida. Assim, se uma marca obteve proteção em país signatário da CUP o Brasil compromete-se a protegê-la em território nacional, independentemente de registro dentro daquele ramo de atividade.

A ausência de registro no país ou em determinado ramo de atividade não implica necessariamente em inexistência de proteção da marca.

Por outro lado, o direito de uso exclusivo concedido ao detentor do registro da marca, todavia, não é absoluto. A Constituição Federal o instituiu como direito fundamental, e delineou seus limites, assim, o diploma infraconstitucional que dispõe sobre a propriedade da marca deve observar tais fronteiras, sob pena de inconstitucionalidade. O artigo 132 da Lei 9.279/96 traz exceções ao direito de propriedade da marca que permitem terceiros a utilizar signo registrado de outrem, sem necessidade de autorização prévia.

Art. 132. O titular da marca não poderá:

I - impedir que comerciantes ou distribuidores utilizem sinais distintivos que lhes são próprios, juntamente com a marca do produto, na sua promoção e comercialização;

II - impedir que fabricantes de acessórios utilizem a marca para indicar a destinação do produto, desde que obedecidas as práticas leais de concorrência;

III - impedir a livre circulação de produto colocado no mercado interno, por si ou por outrem com seu consentimento, ressalvado o disposto nos $\S \S 3^{\circ}$ e $4^{\circ}$ do art. 68; e

IV - impedir a citação da marca em discurso, obra científica ou literária ou qualquer outra publicação, desde que sem conotação comercial e sem prejuízo para seu caráter distintivo.

Assim, por exemplo, se o fictício "Mercadinho XPTO" distribuir folhetos onde, promove os produtos que vende, pode utilizar a figura de uma garrafa de Coca-Cola (que é atualmente uma das 20 marcas reconhecidas como sendo de alto renome pelo INPI) com o signo distintivo visível para anunciar que comercializa o produto. Tal atitude independe de licença ou autorização da detentora do registro da marca, que não pode impedir o uso nestas condições conforme o inciso I do artigo supracitado. O mesmo ocorre se a empresa XYZ, fabricar capas protetoras para serem utilizadas no mais novo aparelho telefônico da Apple (Marca mais valiosa do mundo) e anunciá-las como PIDCC, Aracaju/Se, Ano VIII, Volume 13 no 01, p.277 a 300 Fev/2019 | www.pidcc.com.br 
acessórios para serem utilizadas com o Iphone 7 Master Plus Ultra, a diferença para o primeiro exemplo é que neste caso a fundamentação legal recai sobre o inciso II do art. 132 da Lei de Propriedade Industrial. Conforme nos autoriza o inciso IV citou-se por diversas oportunidades no presente artigo marcas registradas sem a necessidade de autorização prévia e sem que incorrer em transgressão à proteção conferida aos titulares de seus registros.

Pontuadas as características mais relevantes do serviço de links patrocinados e os aspectos mais significativos da proteção das marcas, no contexto deste estudo, pode-se avançar à aplicação dos normativos aos casos concretos.

\section{JURISPRUDÊNCIA DO TRIBUNAL DE JUSTIÇA DE SÃO PAULO}

Iniciou-se esta etapa do estudo com a pesquisa na base de dados jurisprudencial do Tribunal de Justiça do Estado de São Paulo ${ }^{13}$, na oportunidade foram utilizados os seguintes parâmetros: No campo "Pesquisa Livre" foi informada a expressão - marca e "links patrocinados"14 - foram selecionadas no parâmetro "Origem" as opções "2º grau" e "Colégios Recursais"; assinalouse também a opção "Acórdãos" referente ao "Tipo de decisão"; os demais campos em branco. A pesquisa, realizada em 16 de fevereiro de 2017 teve como resultado bruto 74 (setenta e quatro) acórdãos, sendo a data de julgamento mais antiga 28/02/2008 e a mais recente 08/02/2017.

Após tratamento e análise do inteiro teor de cada acórdão do resultado bruto da pesquisa, constatou-se que 30 acórdãos não tratavam do tema de violação da marca em sistema de links patrocinados, mas sim de outros casos de concorrência desleal não relacionados com o objeto do presente estudo, como: titularidade de domínios de sites da internet, violação do direito sobre patentes, falsificação de produtos, uso indevido de marca registrada em estabelecimento comercial, entre outros.

Da amostra inicial restaram 44 acórdãos, dos quais dezessete tratavam-se de Agravos de Instrumento, Agravos Regimentais e Embargos de Declaração. A análise recaiu apenas sobre as apelações que, depois de excluídos os agravos e embargos, totalizaram vinte e sete casos nos quais o tribunal julgou, em grau de recurso, conflitos resultantes da violação do direito de marca em sistema de link patrocinado.

\footnotetext{
${ }^{13}$ Disponível em: <https://esaj.tjsp.jus.br/cjsg/consultaCompleta.do?f=1>. Acesso em 16 Fev 2017

${ }^{14}$ As aspas importam no retorno de acórdãos com a exata expressão "links patrocinados" e o conectivo "e" restringe a pesquisa para resultados que contenham simultaneamente a palavra marca e a expressão links patrocinados.
} 
Das vinte e sete apelações selecionadas, oito, aproximadamente $30 \%$, foram consideradas improcedentes em primeira instância, ou seja, o magistrado entendeu não haver violação do direito sobre a marca pela sua vinculação como palavra-chave em link patrocinado de terceiro não autorizado. Apenas uma dessas oito decisões contrárias ao requente foi mantida pelo Tribunal. Apesar de parte considerável das ações serem consideradas inicialmente improcedentes, em nível recursal, 87,5\% delas foram revertidas. A única decisão de improcedência mantida foi o da Apelação $\mathrm{n}^{\circ}$ 0211917-14.2009.8.26.0100 em que ERGOMAT INDÚSTRIA E COMERCIO LTDA, autora da ação, buscou que a ré INDÚSTRIA E COMERCIO ATLASMAQ LTDA, deixasse de utilizar o termo "Ergomat", da qual a autora possui o registro, como palavra-chave no serviço de AdWords do Google. Ao manter a decisão de $1^{a}$ instância o magistrado salientou o fato de a ré ser revendedora de produtos usados da autora, não podendo esta se opor a sua livre circulação.

\footnotetext{
Ocorre que a requerida, consoante restou demonstrado nos autos, é revendedora dos produtos da autora, conforme notas acostadas a fls. 83/90,, não havendo ilicitude alguma em sua conduta. Consoante constou na r. sentença: "Sendo os produtos em questão usados, ou seja, revendidos após o uso do comprador inicial, sua circulação é livre, independendo de autorização da empresa que o fabrica por não se tratar de revenda comercial de produto novo. Do mesmo modo, não se pode impedir que aquele que vende tais marcas informe ao consumidor a marca dos produtos vendidos, pois negar-lhe tal direito, além de impedir exercício de atividade econômica livre, acarretaria justamente a violação da propriedade intelectual sobre exame"... (TJ-SP; Relator (a): Pedro de Alcântara da Silva Leme Filho; Comarca: São Paulo; Órgão julgador: $8^{\mathrm{a}}$ Câmara de Direito Privado; Data do julgamento: 04/09/2014; Data de registro: 04/09/2014) (grifo no original).
}

A utilização da marca no presente caso tem guarida no art. 132, III da Lei de Propriedade Industrial, que restringe o direito do titular da marca ao proibi-lo de "impedir a livre circulação de produto colocado no mercado interno, por si ou por outrem com seu consentimento".

Este é um dos dois casos, considerando nossa amostra de vinte e sete apelações, em que o tribunal considerou que a utilização de marca registrada em AdWords tinha amparo legal. A outra ação considerada procedente em $1^{a}$ instância e revertida pelo tribunal na apelação $\mathrm{n}^{0}$ 013392484.2012.8.26.0100 julgada em 25 de novembro de 2014. Trata-se de ação vencida em $1^{\mathrm{a}}$ instância pelas autoras LORÉAL e LORÉAL BRASIL COMERCIAL DE COSMÉTICOS LTDA em face de BELEZA.COM COMÉRCIO DE PRODUTOS DE BELEZA E SERVIÇOS DE CABELEIREIRO LTDA, que não se manteve em nível recursal, pois a ré comercializa os produtos da autora, ocorrendo a incidência do inciso I do art. 132 da Lei 9279/96. 
Marca. Uso das marcas das autoras como palavras-chave de link patrocinado contratado pela ré. Ausência de ilicitude. Ré que comercializa os produtos das marcas das autoras vinculadas ao site. Notoriedade do site através das marcas que tem por finalidade alavancar a venda dos produtos. Incidência da norma do art. 132, I, Lei no 9279/96. Ausência de comprovação de que a distribuição dos produtos pelas autoras é realizada de forma seletiva. Autoras que não se desincumbiram do ônus que lhes é imposto pelo artigo 333, I, do CPC. Autoras que deverão arcar com a integralidade dos ônus da sucumbência. Honorários advocatícios fixados em $\mathrm{R} \$ 5.000,00$. Recurso da ré provido, improvido o das autoras. (Relator (a): Maia da Cunha; Comarca: São Paulo; Órgão julgador: $1^{\text {a }}$ Câmara Reservada de Direito Empresarial; Data do julgamento: 25/11/2014; Data de registro: 28/11/2014).

Excetuadas as apelações supramencionadas, nos demais 25 casos, o Tribunal de Justiça de São Paulo considerou como sendo prática ilegal a utilização de marca registrada como palavrachave em sistema de link patrocinado por concorrente da titular do registro.

\subsection{Danos Materiais e Danos Morais}

Os pedidos, dos vinte e sete casos analisados envolvem: (1) que o réu se abstenha de utilizar a marca registrada, em especial nos serviços de links patrocinados e (2) reparação contemplando danos materiais e danos morais. Como visto anteriormente, o Tribunal de Justiça de São Paulo julgou favoravelmente ao titular do registro da marca em $93 \%$ dos casos, gerando ao réu obrigação de indenizar seja por dano moral, dano material ou ambos.

\subsubsection{Dano Material}

Referente aos danos materiais ensina João da Gama Cerqueira (CERQUEIRA, 2012) que as provas dos prejuízos em ações de perdas e danos são particularmente espinhosas de se levantar nos casos de violação dos direitos provenientes do registro de marca, não podendo os juízes exigi-las com severidade, não é incomum de que se ocorra a violação sem que os resultados financeiros da titular do registro sejam visivelmente afetados, porém isto não quer dizer que o prejuízo, de fato não ocorreu.

Ademais, a Lei de Propriedade Industrial traz regulamentação própria sobre a reparação dos danos nos seus artigos 208 a 210.

Art. 208. A indenização será determinada pelos benefícios que o prejudicado teria auferido se a violação não tivesse ocorrido. 
Art. 209. Fica ressalvado ao prejudicado o direito de haver perdas e danos em ressarcimento de prejuízos causados por atos de violação de direitos de propriedade industrial e atos de concorrência desleal não previstos nesta Lei, tendentes a prejudicar a reputação ou os negócios alheios, a criar confusão entre estabelecimentos comerciais, industriais ou prestadores de serviço, ou entre os produtos e serviços postos no comércio.

$\S 1^{\circ}$ Poderá o juiz, nos autos da própria ação, para evitar dano irreparável ou de difícil reparação, determinar liminarmente a sustação da violação ou de ato que a enseje, antes da citação do réu, mediante, caso julgue necessário, caução em dinheiro ou garantia fidejussória.

$\S 2^{\circ}$ Nos casos de reprodução ou de imitação flagrante de marca registrada, o juiz poderá determinar a apreensão de todas as mercadorias, produtos, objetos, embalagens, etiquetas e outros que contenham a marca falsificada ou imitada.

Art. 210. Os lucros cessantes serão determinados pelo critério mais favorável ao prejudicado, dentre os seguintes:

I - os benefícios que o prejudicado teria auferido se a violação não tivesse ocorrido; ou

II - os benefícios que foram auferidos pelo autor da violação do direito; ou

III - a remuneração que o autor da violação teria pago ao titular do direito violado pela concessão de uma licença que lhe permitisse legalmente explorar o bem.

Especial atenção ao artigo 210 e seus incisos, que se referem aos lucros cessantes. A lei aponta três maneiras de se determinar o quantum dos lucros cessantes nos casos de violação dos direitos de propriedade industrial, que inclui o direito marcário. Deverá ser utilizado o critério mais favorável ao prejudicado. Ao passo que as hipóteses previstas nos incisos I e II do artigo 210 podem ser de difícil comprovação, pois nem sempre é factível de se aferir quanto o prejudicado teria ganhado se a violação não ocorresse ou, talvez mais laborioso ainda, medir os benefícios alcançados pelo autor da infração, já a hipótese prevista no inciso III pode ser facilmente estimada e já habilita o prejudicado a receber a reparação dos lucros cessantes. Esta tem sido a posição majoritária do TJ-SP - A presunção do dano material - nas infrações aos direitos de propriedade industrial. Seguem para exemplificar algumas decisões nesse sentido:

Marca. Concorrência desleal. Dano moral que, tanto quanto o material pelo uso parasitário da marca, é presumido. Lesão à honra, reputação e imagem da autora que, ao lado do uso parasitário do nome da sociedade empresária, deve ser indenizado para prestígio da marca e do nome e em benefício do consumidor. Teoria do "ilícito lucrativo" mencionada em embargos infringentes em que prevaleceu a tese sustentada. Arbitramento em R\$50.000,00 que se ajusta aos parâmetros da jurisprudência. Recurso das autoras provido para tanto. (Apelação 0015841-75.2012.8.26.0564 Relator(a): Maia da Cunha; Comarca: São Bernardo do Campo; Órgão julgador: $1^{\mathrm{a}}$ Câmara Reservada de Direito Empresarial; Data do julgamento: 16/03/2016; Data de registro: 18/03/2016)

Propriedade industrial. Comercialização de produtos contrafeitos. Utilização indevida da marca da autora, devidamente registrada perante o INPI. Laudo pericial nesse sentido. Inadmissibilidade. Procedência da ação mantida. 
Danos materiais e morais. Prejuizos in re ipsa. Desnecessidade de prova além da prática da contrafação. Apuração dos danos materiais que se dá em liquidação de sentença, nos termos dos arts. 208 e 210 da Lei $n^{\circ}$ 9.279/96. Danos morais, de seu turno, que, considerando as circunstâncias do caso, merecem mantidos e no valor arbitrado, de $\mathrm{R} \$ 20.000,00$, que se mostrou equilibrado e adequado ao binômio reparação/sanção.

Honorários de advogado. Percentual intermediário compatível com o trabalho desenvolvido. Recurso desprovido. (Apelação 0126225-13.2010.8.26.0100 Relator (a): Araldo Telles; Comarca: São Paulo; Órgão julgador: $2^{\mathrm{a}}$ Câmara Reservada de Direito Empresarial; Data do julgamento: 21/10/2015; Data de registro: 23/10/2015).

MARCA. Contrafação de mercadorias. Apelante que é responsável pela fabricação das mercadorias que levam, indevidamente, a marca de titularidade das apeladas (Oakley). Danos morais e materiais que, pelos recentes precedentes jurisprudenciais, são presumidos. O tão só uso indevido de uma marca de propriedade de outrem, é suficiente a configurar concorrência desleal, em virtude da deterioração da marca, desvio de clientela e lesividade aos consumidores. Apreensão das mercadorias antes de que fossem colocadas em circulação, que não altera essa conclusão, posto que decorrente de atividade alheia à vontade da apelante. Danos materiais que serão apurados em liquidação de sentença, o que se amolda ao disposto nos arts. 208 a 210 da Lei n ${ }^{\circ} 9.279 / 93$, bem como à jurisprudência deste Tribunal. Indenização moral fixada em $\mathrm{R} \$ 40.000,00$ que é razoável e bem atende às peculiaridades do caso. Sentença mantida. Honorários advocatícios majorados para R\$7.000,00 (art. 85, $\S \S 11,2^{\circ} \mathrm{e}$ $3^{\circ}$ do CPC/15). Recurso desprovido. (Apelação. 1042319-69.2014.8.26.0100 Relator (a): Teixeira Leite; Comarca: São Paulo; Órgão julgador: $1^{\text {a }}$ Câmara Reservada de Direito Empresarial; Data do julgamento: 01/09/2016; Data de registro: 01/09/2016).

O entendimento que o dano material é presumido nos casos de violação de marca registrada é reforçado pela jurisprudência do Superior Tribunal de Justiça:

CIVIL E COMERCIAL. RECURSO ESPECIAL. PROPRIEDADE INDUSTRIAL. MARCA. USO INDEVIDO. DANOS MATERIAIS. PRESUNÇÃO. DANOS MORAIS. COMPROVAÇÃO.

1. Os embargos declaratórios têm como objetivo sanar eventual obscuridade, contradição ou omissão existente na decisão recorrida. Inexiste ofensa ao art. 535 do CPC, quando o Tribunal de origem pronuncia-se de forma clara e precisa sobre a questão posta nos

autos, assentando-se em fundamentos suficientes para embasar a decisão, como ocorrido na espécie.

2. Na hipótese de uso indevido de marca, capaz de provocar confusão entre os estabelecimentos e consequente desvio de clientela, desnecessária a prova concreta do prejuízo, que se presume.

3. Há que ser demonstrado o efetivo prejuízo de ordem moral sofrido pelo titular do direito de propriedade industrial, decorrente da sua violação. Na hipótese, configurado pelo protesto efetuado.

4. Recurso especial provido. (Resp n. 1.164.687 - RS (2009/0203347-9), Relator : MINISTRO ANTONIO CARLOS FERREIRA; grifo nosso). 


\subsubsection{Dano Moral}

Quanto aos danos morais resta pacificado na doutrina a possibilidade da pessoa jurídica poder ser sujeito passivo de dano moral. Tal entendimento encontra-se consolidado na Súmula 227 do Superior Tribunal de Justiça - "A pessoa jurídica pode sofrer dano moral.". O que se discute é a necessidade de comprovação dos danos morais nos casos específicos de violação do direito de marca registrada ou se estes podem ser presumidos. Das vinte e sete apelações analisadas, apenas cinco delas tiveram, em segunda instância, negados os pedidos de reparação por danos morais. Digno de nota é o caso da empresa ALSARAIVA COMÉRCIO EMPREENDIMENTOS IMOBILIÁRIOS E PARTICIPAÇÕES LTDA, titular das marcas "HABIB'S" e "RAGAZZO", que ajuizou duas ações em face de PEDIDOS JÁ DIVULGAÇÃO E TECNOLOGIA LTDA, ambas versando sobre a utilização indevida de marca registra em serviço de link patrocinado. As ações tiveram seus pedidos de reparação de danos morais e materiais negados em primeira instância. A requerente e apelou em ambas as ações que foram submetidas ao TJ-SP e julgadas com pouco menos de dois meses entre si, com decisões divergentes no tocante aos danos morais (quanto aos danos materiais foi entendido, em ambos os casos, que são devidos e presumidos).

A apelação 1111763-58.2015.8.26.0100, julgada em 24 de agosto de 2016, considerou que a utilização da marca "RAGAZZO", pela ré em sistema de AdWords, constituiu infração à proteção do registro da marca pertencente à autora, porém em decisão não unanime foi negada a reparação por danos morais conforme termos do relator, que entendeu haver necessidade de efetiva demonstração do dano extrapatrimonial:

\footnotetext{
De resto, o recurso não merece provimento em relação aos danos morais, visto que não está configurada hipótese em que se possa meramente presumir a ocorrência de dano moral, para que a partir daí, por inferência, ser imposta a condenação à respectiva reparação. $\mathrm{O}$ dano extrapatrimonial ocorre quando há abalo do enome social da empresa. É certo que pessoa jurídica não tem honra subjetiva. Não sofre abalos emocionais ou psíquicos, já que estes só podem ser sofridos por indivíduos, por entes vivos, não por ficções jurídicas. Mas a pessoa jurídica tem sim direito à proteção de seu renome. Tem direito ao respeito, à consideração e ao apreço social. Nessa medida, pode padecer de ataque que atinja sua honra objetiva, justamente por gozar de determinada reputação.
}

Porém, o Desembargador Carlos Alberto Garbi, em seu voto vencido, entendeu que a autora faria jus à reparação extrapatrimonial e que o dano moral seria presumido.

Já na apelação no 1111766-13.2015.8.26.0100, julgada em 19 de outubro de 2016 em demanda muito parecida, onde agora a marca utilizada indevidamente era "HABIB'S", além da reparação por danos materiais a ré foi condenada também a pagar indenização no valor de R\$ 
30.000,00 (trinta mil reais) a título de dano moral. O relator justificou a concessão da reparação extrapatrimonial com base na teoria dos ilícitos lucrativos.

\begin{abstract}
No caso em tela, embora a marca da autora não tenha sido exatamente depreciada ou denegrida, o ilícito praticado pela ré violou sua esfera extrapatrimonial, e não pode ficar impune, pena de reiteração da conduta lesiva. Sobreleva-se, aqui, o caráter punitivo da indenização por danos morais. A mais moderna doutrina fala hoje em "ilícitos lucrativos", aqueles que valem a pena ser praticados. Sobre o assunto, observa Rodolphe Mesa que "no contexto dos comportamentos antijurídicos, a teoria do ilícito lucrativo leva o agente a estimar as perdas inerentes à sua condenação, confrontando-as com os benefícios previsíveis que a concretização da atividade ilícita pode gerar; e somente se a receita ilícita for maior do que o montante da sanção que o sujeito agirá, decidindo, em total conhecimento de causa e no âmbito de uma preocupação de racionalidade econômica, transgredir a regra de direito"

(cf. Les feutes lucratives em droit privé, citado por Daniel de Andrade Levy, Responsabilidade Civil de um direito de danos a um direito de condutas lesivas, Atlas, $\mathrm{p}$. 108).

Poder-se-ia questionar se o princípio da reparação integral do dano (art. 944 do Código Civil) não constituiria limite e teto à indenização. Nada impede, porém, de se falar em princípio da reparação integral dos atos ilícitos, abrangendo não somente os prejuízos efetivos sofridos pela vítima, como também os benefícios indevidamente auferidos pelo ofensor.
\end{abstract}

Das vinte e sete apelações analisadas, três delas não fazem menção a dano moral, duas tratam de casos em que foi reconhecida como lícita a utilização da marca registrada como palavrachave, nos termos do artigo 132, incisos I e III da Lei n. 9279/96, das vinte e duas restantes, o dano moral foi considerado indevido em cinco delas, ou seja, em $77 \%$ dos casos a decisão do tribunal foi favorável aos pedidos de reparação de dano moral pelo uso indevido da marca em sistemas de link patrocinado.

\title{
5.2 A Responsabilidade do Google
}

Do total de demandas analisadas em apenas seis delas o Google figurou como réu, sendo que em quatro formou litisconsórcio passivo juntamente com a empresa contratante do seu serviço de AdWords que vinculava seu anúncio às marcas registradas de terceiros.

Para a apuração da responsabilidade do Google faz-se necessária a análise da Lei 12.965/2014, conhecida como Marco Civil da Internet que regulou a responsabilidade civil dos provedores de aplicação. 
5.2.1 Responsabilidade dos provedores de aplicação após a Lei 12.965/2014

O marco civil da internet - Lei $\mathrm{n}^{\mathrm{o}} 12.965$ publicada em 24 de abril de 2014 - encontra-se vigente desde 23 de junho 2014 e não trouxe regulamentação quanto à violação da propriedade industrial no âmbito da internet, pois, sobre propriedade intelectual há apenas um único parágrafo, que versa apenas sobre direito do autor e conexos ( $\S 2^{\circ}$ do artigo 19, abaixo transcrito), e que dependente de regulamentação, ainda inexistente, contudo, regulou em seus artigos 18 a 21 a responsabilidade dos provedores de conexão e dos provedores de aplicação quanto ao conteúdo gerado por terceiros.

Primeiramente deve-se analisar se o Google pode ser considerado, para efeitos legais, um provedor de conexão ou provedor de aplicação. $\mathrm{O}$ art. $5^{\circ}$ do marco civil da internet traz diversas definições entre elas, em seu inciso VII, o que é, para efeitos legais, uma aplicação de internet - "o conjunto de funcionalidades que podem ser acessadas por meio de um terminal conectado à internet" - assim, os buscadores de conteúdo, como o Google, são aplicações de internet. Torna-se então muito relevante, para determinar sua responsabilidade, a leitura do art. 19 do marco civil:

Art. 19. Com o intuito de assegurar a liberdade de expressão e impedir a censura, o provedor de aplicacões de internet somente poderá ser responsabilizado civilmente por danos decorrentes de conteúdo gerado por terceiros se, após ordem judicial específica, não tomar as providências para, no âmbito e nos limites técnicos do seu serviço e dentro do prazo assinalado, tornar indisponível o conteúdo apontado como infringente, ressalvadas as disposições legais em contrário.

$\S 1$ o A ordem judicial de que trata o caput deverá conter, sob pena de nulidade, identificação clara e específica do conteúdo apontado como infringente, que permita a localização inequívoca do material.

$\S 2 \underline{\mathrm{o}} \mathrm{A}$ aplicação do disposto neste artigo para infrações a direitos de autor ou a direitos conexos depende de previsão legal específica, que deverá respeitar a liberdade de expressão e demais garantias previstas no art. $5 \underline{\mathrm{o}}$ da Constituição Federal.

$\S 3$ o As causas que versem sobre ressarcimento por danos decorrentes de conteúdos disponibilizados na internet relacionados à honra, à reputação ou a direitos de personalidade, bem como sobre a indisponibilização desses conteúdos por provedores de aplicações de internet, poderão ser apresentadas perante os juizados especiais.

$\S 4 \underline{\mathrm{o}} \mathrm{O}$ juiz, inclusive no procedimento previsto no $\S 3$ o, poderá antecipar, total ou parcialmente, os efeitos da tutela pretendida no pedido inicial, existindo prova inequívoca do fato e considerado o interesse da coletividade na disponibilização do conteúdo na internet, desde que presentes os requisitos de verossimilhança da alegação do autor e de fundado receio de dano irreparável ou de difícil reparação. (grifo nosso). 
Com o advento da nova lei os provedores de aplicações de internet só poderão responder por danos causados pelo conteúdo gerado por terceiros após ordem judicial específica, portanto, não basta que, aquele que tenha a sua marca indevidamente vinculada a anúncio de empresa rival em sistema de link patrocinado, faça comunicação ou solicitação extrajudicial ao provedor de aplicação e este não a cumpra para que se obtenha do provedor de aplicação reparação do dano causado. Fazse necessária a ordem oriunda do Poder Judiciário e, somente caso haja negativa do provedor posterior a ela, é que este poderá ser responsabilizado.

A lei ainda atribui ao provedor de aplicações o dever de comunicar ao responsável pelo conteúdo que venha a ser tornado indisponível por ordem judicial, sempre que tiver informações de contato do usuário, informações que lhe permitam a ampla defesa e o contraditório em juízo, salvo previsão legal ou decisão judicial fundamentada em contrário.

A partir da vigência do Marco Civil da Internet são estabelecidos parâmetros claros e objetivos para a apuração da responsabilidade dos provedores de aplicação de internet no caso de danos decorrentes de conteúdo gerado por terceiros.

\subsubsection{Responsabilidade em casos concretos antes e após a vigência do Marco Civil da Internet}

Nas vinte e sete apelações analisadas em apenas seis delas o Google figurou no polo passivo da ação sendo que em apenas duas delas houve responsabilização do provedor de aplicação gerando a obrigação de reparar o dano. Nas duas condenações (Apelações $\mathrm{n}^{0}$ 013093508.2012.8.26.0100 e 0218907-50.2011.8.26.0100) a responsabilidade se baseou na teoria do risco.

Importante salientar que não socorre o Google a alegação de que a inviabilidade de juízo prévio de valor acerca da palavra-chave utilizada pelo contratante do serviço do Google AdWords, por se tratar esse de um programa on line, dinâmico e automático, afasta sua responsabilidade. A eleição, pelo requerido, de sistema impediente de controle prévio, acarreta sua responsabilidade acerca de eventuais prejuízos causados a terceiros, sobretudo porque a contratação do aludido programa confere-lhe retorno pecuniário (artigo 884, do Código Civil). É a aplicação da teoria do risco, plenamente cabível no caso concreto. (Apelação no 0218907-50.2011.8.26.0100.)

Se o requerido Google se dispõe a vender anúncios em seu site de pesquisas sem analisar previamente o potencial lesivo do conteúdo inserido por aquele com quem contrata, deve arcar com as consequências de sua omissão. Aplica-se, então, a teoria do risco-proveito.

Se site de buscas delibera contratar com milhares de usuários sem qualquer prévio controle de violação de direitos imateriais alheios, e com isso aufere receitas, mas potencializa o risco de danos, deve responder se o risco se converte em prejuízo real. 
Em outras palavras, se o contrato firmado entre o Google e seu anunciante gera danos a terceiros, ambos os contratantes devem ser responsabilizados.

(Apelação n ${ }^{\circ}$ 0130935-08.2012.8.26.0100)

Tal entendimento foi possível, pois, em ambos os casos, a violação do direito marcário, reconhecida pelo judiciário, ocorreu antes da entrada em vigor da Lei 12.965/2014.

Verificou-se também decisão referente à ocorrência de violação de marca posterior à vigência do Marco Civil da Internet, onde o provedor não foi responsabilizado pela incidência do art. 19 da Lei 12.965/2014. Trata-se de ação impetrada por INSULFILM DO BRASIL LTDA em face de GOOGLE BRASIL INTERNET LTDA, onde se requer a retirada da marca registrada "Insulfilm", de propriedade da autora, da vinculação como palavra-chave em anúncios pertencentes a empresas concorrentes no sistema de AdWords do Google, além da reparação por danos materiais e morais. A ação foi julgada improcedente em primeira instância e na apelação $n^{\circ}$ 1054774-03.2013.8.26.0100, julgada em 17 de janeiro de 2017 o tribunal a considerou parcialmente procedente, decidindo que o provedor de aplicações de internet eliminasse dos resultados de busca contendo a marca registrada da autora os anúncios patrocinados de terceiros, porém negou provimento ao pedido de reparação de danos com base no art. 19 da Lei 12.965/14:

A eventual violação da marca em si, por sua vez, não pode ser diretamente atribuída à apelada, mas aos anunciantes.

Nos moldes do artigo 19 da Lei 12.965/14 (Marco Civil da Internet), o provedor de internet não pode ser responsabilizado por danos decorrentes de conteúdo gerado por terceiro, antes de eventual determinação judicial nesse sentido.

Inviável, assim, o acolhimento da pretensão reparatória, já que apenas nessa oportunidade determina-se a eliminação dos resultados de busca e o impedimento de novos anúncios, quando relacionados à palavra-chave em questão e se tratar de links patrocinados. (Relator (a): Carlos Alberto de Salles; Comarca: São Paulo; Órgão julgador: $3^{\text {a }}$ Câmara de Direito Privado; Data do julgamento: 17/01/2017; Data de registro: 17/01/2017).

\section{CONCLUSÃO}

A jurisprudência do Tribunal de Justiça de São Paulo aponta no sentido de que configura violação à propriedade de marca a utilização desta como palavra-chave em sistema de links patrocinados por empresas concorrentes e não licenciadas ou autorizadas a utilizar o signo distintivo.

O controle prévio, realizado pelo provedor de aplicação de internet, da utilização de marca registrada por terceiros não nos parece factível, exceção feita às marcas de alto renome - por serem protegidas em todos os ramos de atividade - pois, caso o provedor impeça a utilização de 
palavra que consiste em marca registrada por qualquer terceiro, poderá incorrer na transgressão ao artigo 132 da Lei 9279/96 que limita direito do titular de uma marca. Não se pode impedir o comerciante de anunciar os produtos que vende (identificando-os pela marca), ou ainda o fabricante de acessórios a indicar a destinação de seu produto, etc.

O princípio da especificidade da proteção marcária dificultaria muito este controle prévio por parte do provedor de aplicação, isto somado ao modelo de responsabilização dos provedores de aplicação trazido pelo marco civil da internet, deixa a cargo daquele que contrata um serviço de link patrocinado o dever de verificar se os termos que pretende utilizar como palavra-chave não é marca registra - ou depositada anteriormente - de pessoa que atue no mesmo ramo de atividade.

Caso o anunciante utilize marca registrada por outrem para vincular seu anúncio aproveitando-se da fama alheia e desviando clientela, se demandado judicialmente pelo titular da marca, arcará com a reparação de danos materiais, mesmo que o autor não comprove o dano efetivamente sofrido, e há uma forte tendência na concessão também de dano moral.

\section{REFERÊNCIAS}

BARROS, Carla Eugenia Caldas. Manual de Direito da Propriedade Intelectual, Evocati: Aracaju, 2007.

BARBOSA, Denis Borges. Uma Introdução à Propriedade Intelectual. 2 ed. Rio de Janeiro: Lumen Juris, 2010.

BARBOSA, Denis Borges. A Especialidade das Marcas. Universo Jurídico, Juiz de Fora, ano XI, 31 de jan. De 2007. Disponível em:

<http://uj.novaprolink.com.br/doutrina/2946/a_especialidade_das_marcas>. Acesso em: 02 Mar 2017.

CERQUEIRA, João da Gama. Tratado de Propriedade Industrial: Volume II. 3 ed. Rio de Janeiro: Lumen Juris, 2012.

Forbes. 50 marcas mais valiosas do mundo. Disponível em:

$<$ http://www.forbes.com.br/listas/2016/10/50-marcas-mais-valiosas-do-mundo $>$. Acesso em: $17 \mathrm{Fev}$ 2017.

Instituto Brasileiro de Geografia e Estatística - IBGE. Contas nacionais trimestrais. Disponível em: $<$ http://www.ibge.gov.br/home/estatistica/indicadores/pib/defaultcnt.shtm>. Acesso em: 10 Jan 2017.

Instituto Nacional da Propriedade Industrial (Brasil). A criação de uma marca: uma introdução às marcas de produtos e serviços para as pequenas e médias empresas/ Instituto Nacional da 
Propriedade Industrial. - Rio de Janeiro: INPI, 2013.

JACOBSON, Howie. Google AdWords for Dummies. 2 ed. Indianápolis: Wiley Publishing Inc, 2009.

JUNGMANN, Diana de Mello. A caminho da inovação: proteção e negócios com bens de propriedade intelectual: guia para o empresário/ Diana de Mello Jungmann, Esther Aquemi Bonetti. - Brasília: IEL, 2010.

LIMA, Maurício. Veja.com - Radar on-Line "Valor de mercado das empresas brasileiras cresce 53\% em 2016". Disponível em: $<$ http://veja.abril.com.br/blog/radar-on-line/valor-demercado-das-empresas-brasileiras-cresce-53-em-2016/> . Acesso em: 17 Fev 2017.

REQUIÃO, Rubens. Curso de direito comercial. São Paulo: Saraiva, 2003

STAT COUNTER - GLOBAL STATS. Searche Engine Market Share in Brazil: Jan 2016 to Feb 2017. Disponível em: $<$ http://gs.statcounter.com/search-engine-market-share/all/brazil $>$. Acesso em: 01 Mar 2017.

TORRES, Cláudio. Guia Prático de Marketing na Internet para Pequenas Empresas - Cláudio Torres, 2010.

WEBSHOPPERS. Avaliação $\mathbf{3 6 0}^{\circ}$ do primeiro semestre de 2016. Disponível em: <https://www.ebit.com.br/webshoppers $>$. Acesso em: 09 Jan 2017. . Pontos de destaque no ano de 2015. Disponível em:

$<$ https://www.ebit.com.br/webshoppers $>$. Acesso em: 09 Jan 2017. 